\title{
Microwave assisted pyrolysis of Imperata Cylindrica with ionic liquids pre-treatment
}

\author{
AlyaAtira Abdul Keflii ${ }^{1}$, Azduwin Khasri ${ }^{1}$, Nor Munirah Rohaizad ${ }^{1}$ and Mohd Azmier Ahmad ${ }^{2,3 *}$ \\ ${ }^{\prime}$ Department of Chemical Engineering Technology, Faculty of Engineering Technology, Universiti Malaysia Perlis, Kampus Unicity Sungai Chuchuh, \\ Padang Besar, 02100 Perlis, Malaysia \\ ${ }^{2}$ School of Chemical Engineering, Engineering Campus, Universiti Sains Malaysia, 14300 Nibong Tebal, Penang, Malaysia \\ ${ }^{3}$ Solid Waste Management Cluster, Science E Engineering Research Centre, Engineering Campus, Universiti Sains Malaysia, Nibong Tebal, Penang, Malaysia
}

\section{Article Info}

*Corresponding author:
Mohd Azmier Ahmad
Associate Professor
School of Chemical Engineering
Engineering Campus
Universiti Sains Malaysia
14300 Nibong Tebal, Penang, Malaysia
Tel: +604 5996459
Fax: +604 5996908
E-mail: chazmier@usm.my

Received: March 28, 2017

Accepted: April 27, 2017

Published: May 3, 2017

Citation: Kefli AA, Khasri A, Rohaizad NM, Ahmad MA. Microwave assisted pyrolysis of Imperata Cylindrica with ionic liquids pre-treatment. Int J Petrochem Res. 2017; 1(1): $73-75$

doi: $10.18689 /$ ijpr-1000112

Copyright: (c) 2017 The Author(s). This work is licensed under a Creative Commons Attribution 4.0 International License, which permits unrestricted use, distribution, and reproduction in any medium, provided the original work is properly cited.

Published by Madridge Publishers

\begin{abstract}
Pyrolysis of Imperata Cylindrica via microwave irradiation pre-treated with 1-butyl3-methyl-imidazolium tetrafluoroborate (IL-B) and 1-butyl-3-methyl-imidazolium chloride (IL-C) as ionic liquids (ILs) were investigated. The effect of operating variables; microwave power, particle size and IL: biomass mass ratio (MR) towards bio-oil yield were studied. At constant heating time of $20 \mathrm{~min}$ and nitrogen flowrate of $2 \mathrm{~L} / \mathrm{min}$, the optimum pyrolysis conditions of microwave power, particle size and MR were obtained at $700 \mathrm{~W}$, $\leq 300 \mu \mathrm{m}$ and 0.3 , respectively. At this point, pyrolysis Imperata Cylindrica pretreated by IL-B and IL-C have resulted bio-oil yield of $19.07 \%$ and $16.21 \%$, respectively.
\end{abstract}

Keywords: Biomass, Bio-oil, Imperata Cylindrica, Ionic liquid, Microwave, Pyrolysis

\section{Introduction}

Presently the fossil fuel resources supplies are falling off and this situation has created strong attraction in finding other option particularly from renewable biomass sources as alternative energy source. Biomass contains stored energy and can be converted to pyrolysis liquids known as the bio-oils through pyrolysis process [1]. Biomass pyrolysis is defined as the thermal decomposition of the biomass organic matrix which resulted bio-oil, char and gas as products [2]. Particularly bio-oil has been suitable candidates to replace petroleum fuels to be used in various thermal devices. Bio-oil is a kind of hydro carbon with dark brown colour, free flowing liquids with smoky odour. They are complex mixtures of compounds that are derived from the depolymerization of cellulose, hemicellulose and lignin [3].

A number of conventional pyrolysis technologies have been developed such as fixed bed reactor [4], vacuum pyrolysis reactor, transport bed, bubbling fluid bed, circulating fluid bed and rotating cone. However, these technologies are using external heat source which requires high energy consumption and long processing time [5]. In this study, an attempt was made in using microwave heating for pyrolysis of Imperata Cylindrica as biomass. In addition, ILs were used for pre-treatment of the biomass for accelerating the bio-oil production during the microwave heating.

\section{Materials and methods Raw material and catalyst}

The biomass feed stock of Imperata Cylindrica or cogon grass used in this study was obtained from Perlis, Malaysia. The sample was cut into small pieces and dried for 8 hours at $100^{\circ} \mathrm{C}$ in an oven. Then, the samples were milled and sieved into three different ranges of particle sizes of $\leq 300 \mu \mathrm{m}, 300-425 \mu \mathrm{m}$ and $425-600 \mu \mathrm{m}$. The proximate analysis was carried 
out using thermogravimetric analyzer (Perkin Elmer TGA7, USA). The elemental analysis was performed using Elemental Analyzer (Perkin Elmer Series II 2400, USA). Extractives, hemicelluloses, lignin and cellulose concentration of Imperata Cylindrica are shown in Table 1.

Table 1 Proximate, ultimate and component analysis of Imperata Cylindrica

Proximate analysis [wt.\%] Ultimate analysis [wt.\%] Component analysis [wt.\%]

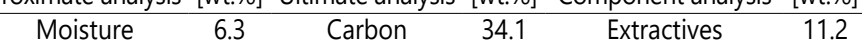

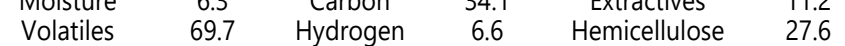

$\begin{array}{llllll}\text { Fixed carbon } & 11.5 & \text { Nitrogen } & 0.8 & \text { Lignin } & 16.5\end{array}$

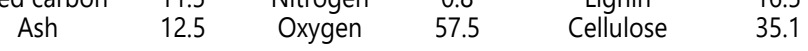

1-butyl-3-methyl-imidazolium tetrafluoroborate and 1-butyl3-methyl-imidazolium chloride supplied by Merck (M) Sdn. Bhd with purity of $99 \%$ were used without any further purification.

\section{Pre-treatment of ILs}

Before pyrolysis process, the Imperata Cylindrica was pre-treated with IL aqueous solution. For IL to biomass mass ratio (MR) of $0.1, \mathrm{IL}$ aqueous solution was prepared by dissolving $1.0 \mathrm{~g}$ of IL-B or IL-C into $34 \mathrm{~mL}$ of distilled water. 10 $\mathrm{g}$ of Imperata Cylindrica was immersed in the IL aqueous solution followed by heating at $80^{\circ} \mathrm{C}$ for 2 hours. Using the same procedures, various MR were prepared by changing the amount of IL added in distilled water.

\section{Microwave-assisted pyrolysis process}

The schematic diagram of the apparatus set-up isshown in Figure 1. The pyrolysis of biomass was carried out using a modified commercial microwave with a frequency of $2.45 \mathrm{GHz}$. The quartz tube reactor with $6 \mathrm{~cm}$ internal diameterand $14 \mathrm{~cm}$ height was installed in the cavity of the microwave. The microwave was equipped with two condensers in series to cool down the vapour generated during pyrolysis process. $5 \mathrm{~g}$ of the pre-treated biomass was placed into the quartz tube reactor. The $\mathrm{N}_{2}$ gas was purged for 5 minutes at $2 \mathrm{~L} / \mathrm{min}$ to ensure inert condition of the system. All experiments were conducted using heating time of 20 minutes and $\mathrm{N}_{2}$ gas flowrate of $2 \mathrm{~L} / \mathrm{min}$. The bio-oil produced was collected in a conical flask. For study the effect of microwave power, particle size of less than $300 \mu \mathrm{m}$ and MR of 0.3 were used. For study the effect of particle size, microwave power and MR of $700 \mathrm{~W}$ and 0.3 were used. For study the effect of MR on bio-oil yield, the microwave power of $700 \mathrm{~W}$ and particle size of less than $300 \mu \mathrm{m}$ were used.

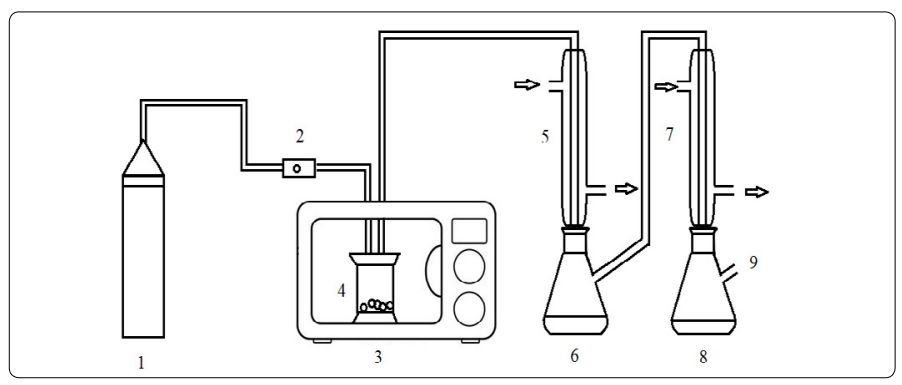

Description:

$\begin{array}{lll}\text { 1. Nitrogen gas cylinder } & \text { 4. Quartz tube reactor } & \text { 7. Condenser } \\ \text { 2. Gas flow meter } & \text { 5. Condenser } & \text { 8. Bio-oil collector flask } \\ \text { 3. Microwave oven } & \text { 6. Bio-oil collector flask } & \text { 9. Gas release }\end{array}$

\section{Results and discussion}

\section{Effect of microwave power and particle sizes on pyrolysis of Imperata Cylindrica}

Figure 2 shows the distribution of products yield using various microwave power. The yield of solid char was the highest followed by gas and bio-oil products. The bio-oil yield first increased and then decreased with an increase in microwave power (Fig.2). The maximum yield of bio-oil of $15.3 \%$ was obtained at $700 \mathrm{~W}$ and decreased to $12.5 \%$ at $800 \mathrm{~W}$. The pyrolysis reaction is an endothermic process, so the yield of the bio-oil increased by raising the microwave power. This is because as microwave power increased, more strong organic bonds in the sample were broken [6]. However, the bio-oil yield was decreased at $800 \mathrm{~W}$ due to secondary thermal decomposition of some of the compounds of bio-oil yielding gaseous product under higher power [7]. Therefore, the gas yield substantially increased but the liquid yield substantially decreased with increasing microwave power, whereas the reduction in the solid char yield was not so obvious. This may imply that, when product vapors are released by the devolatilization of biomass pyrolysis, more hydrocarbons in the vapors can be converted into permanent gases at higher power.

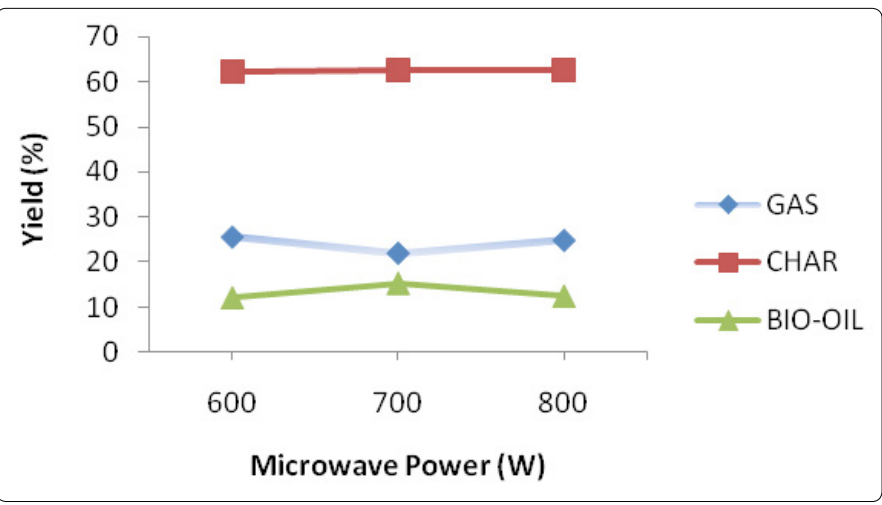

Figure 2. Effect of microwave power on product yield

Figure 3 shows the effect of particle sizes on the product distribution using microwave power at $700 \mathrm{~W}$.It can be seen that char and bio-oil yields decreased where as gas yield increased as the particle size increased up to $425-600 \mu \mathrm{m}$. The maximum bio-oil yield of $13.9 \%$ was obtained at particle size less than $300 \mu \mathrm{m}$. This is due to the fact that smaller particles promote the heat and mass transfer to form uniform temperature within particles during pyrolysis, thereby enhancing the bio-oil production and secondary cracking of solid residue by restraining the vapour formation. At lower particle size ranges, more residence time of volatiles inside the reactor results in the heavier molecules cracking in to lower molecules and thus lead to rise of gaseous product [4]. Larger particles will heat up more slowly compared to small particles, so the average particle temperature is lower and hence affects the product yield. Particle size less than $300 \mu \mathrm{m}$ and microwave power of $700 \mathrm{~W}$, which gave the highest biooil yield were used in the following section.

Figure 1. Schematic layout of microwave pyrolysis experimental setup 


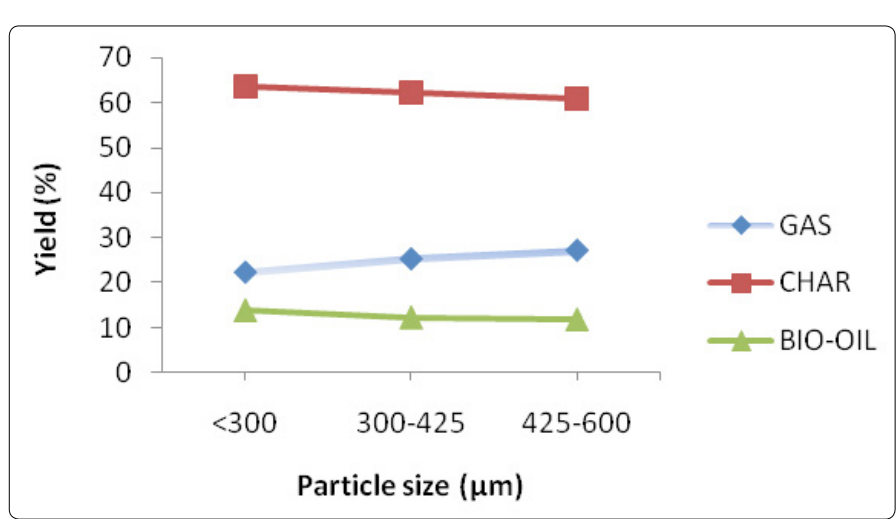

Figure 3. Effect of particle size on product yield

\section{Effect of MR on pyrolysis of Imperata Cylindrica}

Figure 4 shows that lowest bio-oil yield produced without IL under microwave heating indicates that the presence of ILS showed positive effect on the bio-oil yield. This is due to the capability of ILs to adsorb microwave energy effectively, leading to rapid rise of reaction temperature and the promotion of biomass pyrolysis and thus results in increased of bio-oil yield. Furthermore, the pre-treatment has been trialled to reduce the lignin content, generally the most thermally resistant compound in the lingo cellulosic biomass, so that the pyrolysis bio-oil yields can be enhanced. Lateef et al. stated that ILs could interact with terminal $\mathrm{OH}$ groups of lignin, subsequently disrupting the internal network within the lignin molecule, resulting in the dissolution of lignin [8]. As can be seen in the figure, both ILs have shown increase pattern when the MR was increased. However, IL-B shows better performance than IL-C in producing bio-oil. The bio-oil yield produced for IL-B and IL-C were between 15.54 to $19.07 \%$ and 13.12 to $16.21 \%$, respectively. Although both ionic liquids possessed the same cation but different anion $\left(\mathrm{Cl}^{-}\right.$and $\left.\mathrm{BF}_{4}^{-}\right)$. In addition, IL-B anion was found to be more efficient in the depolymerization of cellulose and hemicelluloses during the pretreatment step thus more bio-oil was produced compared to IL-C [9]. Therefore, it can be concluded that anions of ILS have important effect on the dissolution of cellulose, hemicellulose and lignin component [10].

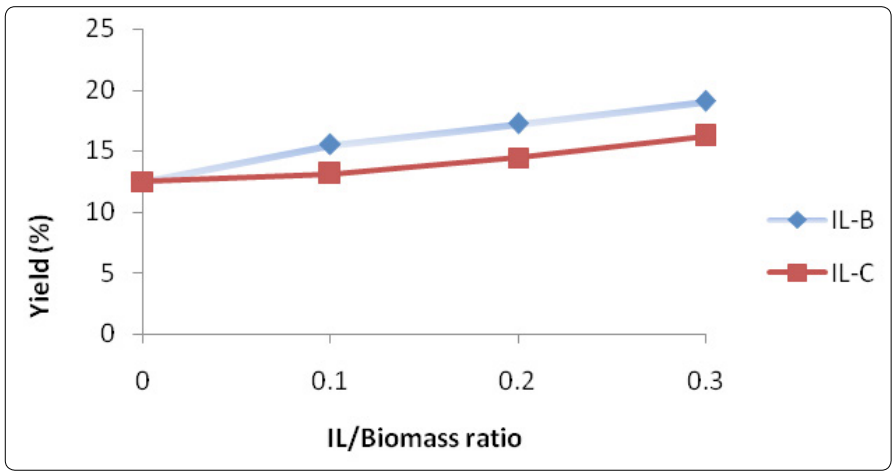

Figure 4 Effect of MR on bio-oil yield

\section{Conclusion}

The optimum conditions for pyrolysis of Imperata Cylindrica using microwave heating which pre-treatment with two ILs were obtained. Under the optimum conditions of microwave power of $700 \mathrm{~W}$, particle size less than $300 \mu \mathrm{m}$ and MR of 0.3 , the maximum bio-oil yield of $19.07 \% 16.21 \%$ for sample treated with IL-B and IL-C, respectively.IL-B shows better performance than IL-C in producing bio-oil. This study shows that the pre-treatment of biomass using ILs prior to pyrolysis had successfully increased the bio-oil yield. Thus, ILs pretreatment showed optimistic outcome on the pyrolysis of biomass under microwave heating.

\section{Acknowledgements}

This research was supported by Ministry of Higher Education, Malaysia (MOHE) under Fundamental Research Grant Scheme (FRGS) through the project number 9003-00382.

\section{References}

1. McKendry P. Energy production from biomass (part 1): Overview of biomass. Bio Res Tech. 2002; 83(1): 37-46. doi: 10.1016/S09608524(01)00118-3

2. Tao K, Vladimir S, Tim JE. Lignocellulosic biomass pyrolysis: A review of product properties and effects of pyrolysis parameters. Renewable and Sustainable Energy Reviews. 2016; 57: 1126-40. doi: 10.1016/j. rser.2015.12.185

3. Lu Q, Li WZ, Zhu XF. Overview of fuel properties of biomass fast pyrolysis oils. Energy Conversion and Management. 2009; 50(5): 1376-83. doi: 10.1016/j.enconman.2009.01.001

4. Azduwin K, Ridzuan MJM, Hafis SM, Amran T. Slow pyrolysis of ImperataCylindrica in a fixed bed reactor. Int J Biol Ecol Envir Scien. 2012; 1(5): $176-80$.

5. Salema AA, Ani FN. Microwave-assisted pyrolysis of oil palm shell biomass using an overhead stirrer. J. Anal. Appl. Pyrol. 2012; 96: 162-72. doi: 10.1016/j.jaap.2012.03.018

6. Du J, Liu P, Liu ZH, Sun DG, Tao CY. Fast pyrolysis of biomass for bio-oil with ionic liquid and microwave irradiation. Fuel Chem Tech J. 2010; 38(5): 554-59. doi: 10.1016/S1872-5813(10)60044-8

7. Motasemi F, Afzal MT. A review on the microwave-assisted pyrolysis technique. Energy and Sustainable Energy Reviews. 2013; 28: 317-30. doi: 10.1016/j.rser.2013.08.008

8. Lateef $H$, Grimes $S$, Kewcharoenwong $P$, Feinberg BJ. Separation and recovery of cellulose and lignin using ionic liquids: a process for recovery from paper-based waste. Chem. Technol. Biotechnol. 2009; 84(12): 1818-27. doi: 10.1002/jctb.2251

9. Muhammad N, Omar WN, Man Z, Bustam MA, Rafiq S, Uemura Y. Effect of ionic liquid treatment on pyrolysis products from bamboo. Ind. Eng. Chem. Res. 2012; 51(5): 2280-89. doi: 10.1021/ie2014313

10. Wang J, Zheng $Y$, Zhang $S$. The application of ionic liquids in dissolution and separation of lignocellulose, in: K. Eguchi (Ed.). Clean Energy Systems and Experiences, InTech. 2010; 71-84. 